\title{
Discussion of Some Questions in Teaching Gear Strength Design
}

\author{
Haijun Mo \\ South China University of Technology \\ Guangzhou,China \\ mohj@scut.edu.cn \\ Jiajun Zhou \\ South China University of Technology \\ Guangzhou,China
}

\author{
Zhisheng Lin \\ South China University of Technology \\ Guangzhou,China \\ Huarong Qiu \\ South China University of Technology \\ Guangzhou,China
}

\begin{abstract}
Gear strength is one of most important part in mechanical design. Several crisis problems will be discussed in the paper which often confused and misunderstood about the calculation of the gear strength including the failure mode of gear, bending fatigue strength design, touching fatigue strength design, etc. The development of gear strength design in history and the current situation are also referred. This article can be referenced for those people that teaching gear and other mechanical design. Besides, it can also help them get a deeper comprehensive and better improvement on gear design and its background.
\end{abstract} design

Keywords- teaching gear; gear failure mode; gear strength

\section{INTRODUCTION}

Gear transmission is one of the most important transmission in mechanical transmission. More than 300 years $\mathrm{BC}$, Aristotle, an ancient Greek philosopher, has expounded bronze or iron gear transmission. Between 17th century and the early 18 th century, people began to study the strength of gear. After the industrial revolution, the technology of gear got rapid development and the gear transmission in the mechanical field are widely application. Currently, the calculation method of gear strength design mainly come from International Standardization Organization(ISO), The American Gear Manufacturers Association(AGMA), The Japan Society of Mechanical Engineers(JSME), and British Standard(BS),etc[1]. However,During teaching mechanical design especially teaching gear, the author found that in many gear design handbooks and textbooks, the knowledges of gear strength design is described too simple for readers to understand. In this paper, several problems about gear design are analyzed deeply, such as failure mode of gear, the history and status of gear strength design. Historical origins of gear strength design in China and some confusions in gear design are also been explored. Through in-depth analysis, it's better for students to understand the meaning and context of the design formula of gear.

\section{DISCUSSION ON GEAR FAILURE MODE}

Gear in the transmission process will appear various forms of failure, and even lose its transmission capacity. The failure mode of gear transmission relate to material, heat treatment, lubrication conditions, magnitude of load and direction, rotation speed and so on. The study of the gear failure is a development process. In the middle of the $18^{\text {th }}$ century, people started to research the failure of gear and have a preliminary understanding about friction and wear, pitting and scuffing. In 1928, Buckingham published papers about the wear and tear of gear, and the tooth surface failure had been divided into six kinds of failure modes.In 1939, Rideout put gear damage into eight forms.In 1967,Niemann drew a limited relation graph of involute gear's four failure modes based on a large number of experiments. And he pointed out that the main factor influencing the soft tooth surface gear's load capacity is pitting when the gear' rotational speed is low. And for hardened gear, the main influence factor is gear breaking. But for high-speed \& heavy-duty gear, the impact factors are often the scuffing [2-3]. Since the 1950s, some countries have classified the gear damage in the form of standard and stipulated nomenclature, causes of characteristics and so on. Such as AGMA in 1951, gear's damage was divided into two categories, one is tooth surface failure, including wear, plastic deformation, scuffing, surface fatigue, and the other is gear breaking. In 1968 Austrian national standard specified the nomenclature of gear's damage [4-5].

In 1983, China promulgated national standard of nomenclature, characteristics and cause of the gear tooth failure[6]. The gear's damage form is divided into five categories, that is wear, tooth surface fatigue, scuffing, plastic deformaiton,gear breaking and other damages,a total of 26 kinds of failure modes.

In 1997, China issued a new national standard. At present, gear failure modes have been simplified in most of the mechanical design textbooks and mechanical design handbooks, and generally divided into five categories, namely gear breaking, fatigue pitting, scuffing, wear and plastic deformation [7-9]. 


\section{THE DISCUSSION OF THE GEAR STRENGTH DESIGN}

\section{A. The Calculation of Tooth Root Bending Strength}

In 1785, Watt put forward the calculation method of tooth root bending strength base on the assumption that the tooth become plate cantilever beam of rectangular cross section. After that, a variety of bending strength calculation formula appeared. In 1893, Lewis has published a tooth bending strength calculation formula, determining dangerous section with inside parabola method. This method is called "parabola method"[10], as shown in fig1.

After that, various types calculation of gear bending strength appeared, such as $30^{\circ}$ tangent method, Niemann method, Buckingham method, etc. In 1980, the ISO proposed "The basic principle of involutes cylindrical gear load capacity" (ISO6336-1980), released the tooth bending strength and tooth surface contact strength calculation method [11-13]。

For a long time, gear strength calculation method has been chaotic in china, there is no uniform standard, resulting some problems in the production, scientific research and teaching. Then, in 1981 China established "load capacity calculation method for the involute cylindrical gear" national standard group, rooted in ISO6336-1980, to carry out comprehensive research work。In 1983, the involute cylindrical gear load capacity calculation method of national standard is promulgated。

At present, the design of the gear bending strength formula in china is basically the $30^{\circ}$ tangent method[14-16], i.e., As with the centerline into a 30 degree angle and tangent to the gear root fillet, the two tangent point line is the tooth root dangerous section position. as shown in Figure 2.

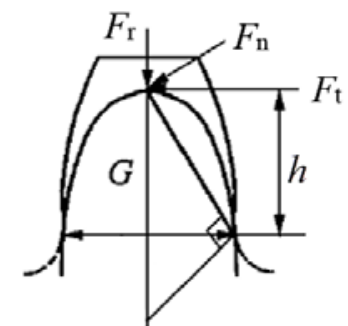

Figure 1. The parabolic method.

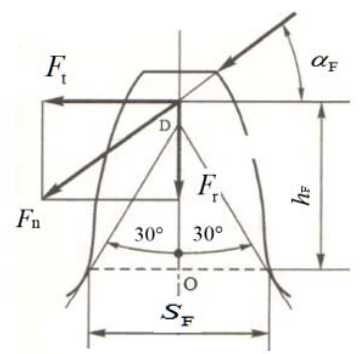

Figure $2.30^{\circ}$ tangent method.
In addition, there are many coefficient in the bending fatigue strength formula, including dynamic load coefficient, coefficient of load distribution among gear teeth, tooth load distribution coefficient, and the coefficient of tooth profile, etc. Tooth shape coefficient is related to the number of teeth, has nothing to do with module. But, in many mechanical design handbooks and other textbooks, the tooth shape coefficient is not explained in detail, and it is not easy to understand. In this unit, the tooth shape coefficient will be detail analyzed.

As shown in Figure 2, the tooth root bending stress is:

$$
\sigma_{F}=\frac{M}{W}=\frac{F_{n} h_{\mathrm{F}} \cos \alpha_{\mathrm{F}}}{b S_{\mathrm{F}}^{2} / 6}=\frac{K F_{\mathrm{t}}}{b m} \frac{6\left(\frac{h_{\mathrm{F}}}{m}\right) \cos \alpha_{\mathrm{F}}}{\left(\frac{S_{\mathrm{F}}}{m}\right)^{2} \cos \alpha}
$$

We let $Y_{\mathrm{F}}=\frac{6\left(\frac{h_{\mathrm{F}}}{m}\right) \cos \alpha_{\mathrm{F}}}{\left(\frac{S_{\mathrm{F}}}{m}\right)^{2} \cos \alpha}$

Where $\alpha$ is the pitch circle pressure angle, $\alpha_{\mathrm{F}}$ is the addendum circle pressure angle, $m$ is gear modulus, $b$ is width of gear.

As we can see, $Y_{\mathrm{F}}$ is related to gear shape and its geometric parameters, so it is called tooth shape coefficient. According to the principle of gear, the change of the number of teeth will cause the change of parameters such as $h_{\mathrm{F}}, S_{\mathrm{F}}, a_{\mathrm{F}}$, etc. Because $h_{\mathrm{F}}, S_{\mathrm{F}}, a_{\mathrm{F}}$ is proportional to the module of gear, the module of gear can be simplified by reduction of a fraction in the Equation(1). Therefore, the tooth shape coefficient is not affected by the modulus, and only related to the number of teeth, the fewer the tooth, the smaller $Y_{\mathrm{F}}$.

\section{B. The Influence on Bending Stress by the Gear Compressive Stress}

According to the $30^{\circ}$ tangent method and stress analysis of gear, force $F_{\mathrm{n}}$ can be moved to the centerline of gear tooth and divided into the two forces, that is circumference force $F_{\mathrm{t}}$ and radial force $F_{\mathrm{r}}$. The $F_{\mathrm{t}}$ leading the tooth root bending stress, and the $F_{\mathrm{r}}$ leading the compression stress. So the dangerous section of gear is the combination of bending stress and compression stress.

However, in the gear design handbooks and textbooks, the compression stress is not considered in the calculation of gear bending strength, and even ignored. But why the compression stress can be ignored, few people made the further investigation, in this unit, this problem will be analyzed.

As shown in fig2, the bending stress is shown in equation(1), and the compression stress is: $\sigma_{y}=\frac{F_{n} \sin \alpha_{\mathrm{F}}}{b S_{\mathrm{F}}}$. Setting $O D=\mathrm{h}^{\prime}$, so $S_{\mathrm{F}}=2 h^{\prime} \tan 30^{\circ}$, we can get: $\frac{\sigma_{y}}{\sigma_{F}}=\frac{\tan 30^{\circ} \cos \alpha}{3} \frac{z}{z+2} \frac{h^{\prime}}{h_{\mathrm{F}}}$

As $\frac{h^{\prime}}{h_{\mathrm{F}}}$ is a constant and it is less than 1 , so, $\frac{\sigma_{y}}{\sigma_{F}}$ is decide by tooth number $z$. we let $\xi=\frac{\sigma_{y}}{\sigma_{F}}$, it reflect compressive stress influence on the bending stress. The co-relationship of $\xi$ and tooth number as shown in fig3, 


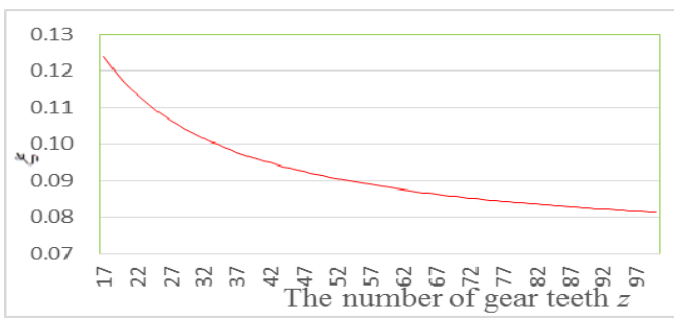

Figure 3 . The correlation between $\zeta$ and the number of teeth

It can be seen that compressive stress influence on bending stress is associated with teeth number, and has nothing to do with module of gear, the number of teeth is fewer, the larger the impact, conversely, the less the impact. The minimum bending stress is about $8 \%$ of the maximum bending stress, especially when $\frac{h^{\prime}}{h_{\mathrm{F}}}<1$, compressive stress is smaller and can be neglected.

Therefore, in order to simplify the calculation, only the gear tooth bending stress is considered when calculating the bending strength.

\section{The Calculation of Contact Fatigue Strength of Gear}

The calculation of the surface contact strength aims at studying the pitting corrosion fatigue failure of the gear surface. In1881, Hertz put forward the formula of the load distribution on the contact surface when two cylinders was contacting, which was used to be the theoretical basis of the gear surface strength calculation and as shown in Figure 4.

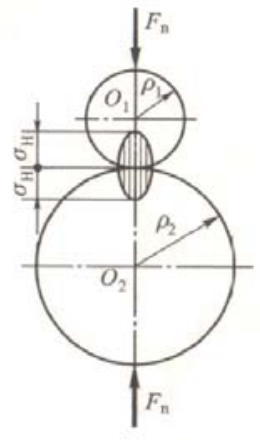

Figure 4. The Hertz contact stress model.

According to the theory of Hertz contact stress, the maximal contact stress generates in the contact area under the load is

$$
\sigma_{H}=\sqrt{\frac{F_{n}}{\pi b} \cdot \frac{\frac{1}{\rho_{1}}+\frac{1}{\rho_{2}}}{\frac{1-\mu_{1}^{2}}{E_{1}}+\frac{1-\mu_{2}^{2}}{E_{2}}}}
$$

Where $\mu_{1}, \mu_{2}$ are Poisson ratio, $\rho_{1}, \rho_{2}$ are the radius of curvature of the two cylinders.

In 1898, based on the normal force, Lasche applied the pressure principle to study the gear surface contact fatigue strength. In 1908, Vidki, from Austria, made the Hertz contact stress of two cylinder theory to apply to the calculation of the gear surface stress and had drawn the variation diagram of the maximal contact stress along the engaging line. In 1932, according to the experimental data, the English BS put forward the basis surface stress to calculate the gear surface strength. In 1940, the American AGMA used the calculation of maximal contact stress of the heaviest load point on the gear surface. In 1949, Buckingham put forward the method to calculate the contact stress on the pitch, which is less than the allowable value. In 1954, Niemann chose the rolling pressure at the heaviest load point [17-18].

Now, in China, the Hertz formula is the basic theory in calculating the gear surface contact strength, i.e. choose the Hertz stress to be the index of pitting corrosion failure.

$$
\text { Set } \frac{1}{\rho_{\Sigma}}=\frac{1}{\rho_{1}}+\frac{1}{\rho_{2}}=\frac{2}{d_{1} \sin \alpha} \frac{i+1}{i} \text {.So, the basic }
$$

formula of gear surface contact strength can be obtained as below.

$$
\begin{aligned}
& \sigma_{H}=Z_{E} \mathrm{Z}_{\mathrm{H}} \sqrt{\frac{2 K \mathrm{~T}_{1}}{b d_{1}^{2}} \frac{i+1}{i}} \leq\left[\sigma_{H}\right] \\
& \text { Where } \mathrm{Z}_{E}=\sqrt{\frac{1}{\pi\left[\frac{1-\mu_{1}^{2}}{E_{1}}+\frac{1-\mu_{2}^{2}}{E_{2}}\right]}}, \mathrm{Z}_{\mathrm{H}}=\sqrt{\frac{2}{\sin \alpha \cos \alpha}}
\end{aligned}
$$

For the standard gears, $\alpha=20^{\circ}$, so $\mathrm{Z}_{\mathrm{H}} \approx 2.5$.

There are lots of versions about the formula of gear surface contact strength in the mechanical design handbooks or textbooks. Among them, the most common one is to simplify the equations of the steel gear, That is

$$
\sigma_{H}=671 \sqrt{\frac{K T_{1}}{b d_{1}^{2}} \frac{i \pm 1}{i}} \leq\left[\sigma_{H}\right]
$$

Where $T_{1}$ is torque of gear, $d_{1}$ is diameter of pitch circle, $i$ is transmission ratio, $\left[\sigma_{\mathrm{H}}\right]$ is allowable stress.

\section{The Calculation of Scuffing Strength of Gear}

Another common failure of the gears is scuffing. Scuffing can be divided into cold scuffing and hot scuffing. For the high speed and heavy load, because of the high instantaneous temperature and the large sliding velocity, it can result to hot scuffing easily. While for the low speed and heavy load one, because of the high stress among the tooth surfaces, it can result to the destruction of the oil slick and occur cold scuffing.

For the calculation of the scuffing strength of gears, there are two basis theories. One of them is based on the value of $P v$, which is the product of the pressure and speed. Another one is Bullock algorithm based on the temperature of the tooth surface. In 1975, Winter raised up the integral temperature method. Now the ISO standard focuses on these two methods. However, the calculation of scuffing strength of the gears is seldom introduced in textbooks in China. Until 2003, China issued the nation standard of calculation of scuffing load capacity of cylindrical, bevel and hypoid Gears. This 
standard almost bases on the standard of ISO/TR 13989-2000 [19-20].

Someone experts trying to stipulate the oil film thickness in the tooth surface as the scuffing criterion according to the elastic hydrodynamic lubrication theory[21-22].

At present in China, many mechanical design textbooks generally provide only two calculation methods, i.e. the bending strength calculation method and tooth surface contact strength calculation method but without scuffing strength calculation formula.

\section{CONCLUSION}

In this paper, gear strength design in the teaching of mechanical design has been analyzed and discussed. The history and current situation of gear strength design have been introduced in detail, as well as puzzling problems and solutions in the process of the gear strength design. Research indicates that compressive stress has limited effect on bending stress in the calculation of bending fatigue strength of gear. But when needed for accurate calculation, its effects should be considered. The research in this paper can help students better understand the related contents in the design of the gear and lay a sound foundation for future work in mechanical design.

\section{REFERENCES}

[1] Changlin Wu,Yunfei Lv. Comparison between ISO and AGMA Gear Strength Rating Methods for Involute Cylindrical Gears[D], Huazhong University of Science \& Technology,2011.

[2] Buckingham,E. Super Gear Design, McGraw-Hill, New York, Academic, 1928:126-130

[3] H.winter. The Development of Gear Load Capacity and Calculation Methods [J].Gear, 1986, 10 (6):31-42.

[4] American Gear Manufactures Association. AGMA 427. 01. Information Sheet-Systems Considerations for Critical Service Gear Drives. Alexandria , 1994.

[5] Rongxun Jiang . Analysis of Calculation Methods of Gear Strength[J]. Journal of Zhejiang University of Technology, 1986 (4) :87-94.

[6] GB/T3481-1983. Nomenclature, Characteristics, Causes of Gear Tooth Failure[S],1983.

[7] Lianggui Pu. Design of Machinery(The Eighth Edition) [M],Beijing: Higher Education Press.2006.

[8] Ping Huang, Wenjian Zhu. Fundamentals of Mechanical Design [M],Beijing:Science Press,2009.

[9] Mengzhou Zhu. Handbook of Mechanical Engineer [M],Beijing:China Machine Press,2002.

[10] Lewis,W. Investigation of The Strength of Gear Teeth. Pro. Eng. Club Phild.1893:29-35.

[11] ISO 9085:2002 Calculation of Load Capacity of Spur and Helical Gears-Ap2 Plication for Industrial gears[S],2002.

[12] Xiaoan Liu, Changxin Yan. Introduction of National Standard of Methods for The Calculation of Load Capacity of Involute Cylindrical gears [J], Gear, 1983, 7 (4) :1-89.

[13] GB/T3480-1983. Methods for The Calculation of Load Capacity of Involute Cylindrical gears[S],1983.

[14] Changiiang Zhou. Comparative Study of Calculation of Gear Drive Design by Two Standards[J], Journal of Mechanical Transmission, 2006, 30 (3):9-10.

[15] Zhengwei Xiao. A Little Discussion for The Toothed Coefficient of the Involute Cylindrical Gear, Journal of Xiangtan University (Nature Science) , 1985, (1):129-131.
[16] Zhan Zhang. Calculation Methods of Gear Strength[J], Journal of Mechanical Transmission, 1980 (4) :1-9.

[17] Aiping Hu.Study on The Contact Strength Calculation of Standard Cylindrical Spur Gear Transmission[J]. Journal of Machine Design, 2008, 25(11):45-47.

[18] Huirong Meng. On The Problems of surface Pressure Encountered in the Calculation of Gear Load Carrying Capacity[J].Journal of China University of Mining \& Technology, 1980 (2) : 73-88.

[19] GB-Z6413.1-2003 Calculation of Scuffing Load Capacity of Cylindrical, Bevel and Hypoid Gears[S]. 2003.

[20] ISO/TR 13989-1:2000, Calculation of Scuffing Load Capacity of Cylindrical, Bevel and Hypoid Gears[S],2000.

[21] Rongrong Zhao. Study of the Effect of Lubricant Viscosity Temperature Property on the Gear Scuffing Load[D]. Northeastern University, 2012.

[22] Yongzheng Sun, Rupeng Zhu.Calculation of mean Fricaion Coefficient in Scuffing Strength for Gear Drive with Meshing Beyond Pitch Point[J], Journal of Aerospace Power,2013,28(9):1418-1423. 